\title{
Edith Stein e o pensamento medieval: continuação da fenomenologia husserliana por uma filosofia do ser
}

\author{
Edith Stein and the medieval thought: \\ continuation of husserlian phenomenology by a philosophy of being
}

\section{Juvenal Savian Filho*}

Universidade Federal de São Paulo, Guarulhos, SP, Brasil

\section{Resumo}

Por uma breve contraposição com o modo como Husserl evoca o pensamento medieval, este artigo pretende explorar a especificidade de Edith Stein em sua relação com autores medievais. A filósofa não é uma simples repetidora de formas medievais de pensar (como também não se tornou uma tomista), mas uma fenomenóloga que revive razões de autores medievais e busca os fundamentos de uma filosofia do ser conjugável com a fenomenologia husserliana.

Palavras-chave: Edith Stein. Pensamento medieval. Fenomenologia. Filosofia do ser. 


\section{Abstract}

By a brief contrast with Husserl's mode of evoking medieval thought, this article aims to explore the specificity of Edith Stein in her relationship with medieval authors. The philosopher is not a simple repeater of medieval ways of thinking (as she did not become a Thomist), but a phenomenologist who revives some reasons of medieval authors and seeks the foundations of a philosophy of being associable with Husserlian phenomenology.

Keywords: Edith Stein. Medieval thought. Phenomenology. Philosophy of being.

\section{Introdução}

A fim de aproximar-nos melhor da especificidade de Edith Stein, cabe dizer previamente uma palavra sobre a relação entre a fenomenologia husserliana e as formas de pensamento desenvolvidas na Idade Média.

Costuma-se afirmar que Husserl aprendeu a teoria da intencionalidade com Brentano, e que este, por sua vez, a aprendeu com os medievais. No entanto, essa afirmação demanda esclarecimentos. Husserl não se dedicou a um estudo sistemático de formas medievais de pensamento nem recebeu influência direta de alguma delas e menos ainda conservou alguma dessas formas em seu trabalho filosófico. Aliás, se Husserl realmente tivesse estudado autores medievais, principalmente no ambiente de redescoberta dessas formas em seu caráter histórico (como começava a ser praticado no início do século XX), seguramente não teria emitido certos juízos claramente equivocados nas referências vagas que faz aos medievais (dando a entender, por exemplo, que os considerava "realistas ingênuos"). Mesmo Martin Heidegger, que - mais do que Husserl - estudou sistematicamente autores medievais, apenas com muita dificuldade, como bem mostrou Olivier Boulnois (1999), pode ser considerado um pensador cuja filosofia sofreu alguma influência real de formas filosóficas elaboradas na Idade Média, até porque sua singular hermenêutica talvez não tenha sido justa com os pensadores interpretados.

Precisamente quanto à teoria da intencionalidade e ao papel do pensamento medieval na formação da fenomenologia husserliana, 
convém lembrar que Husserl nunca reivindicou uma filiação a nenhum autor medieval. Ele fez apenas uma ou outra associação, rara e brevíssima, entre a relação intencional (relação entre o conhecimento e o objeto) e a concepção da inexistência, inhabitação ou pericorese intencional/mental de um objeto, tal como Franz Brentano dizia encontrar nos "escolásticos" (cf., por exemplo, HUSSERL, 1968, p. 366369). Além disso, mesmo que tenha existido alguma teoria medieval da intencionalidade tal como compreendida por Brentano, parece mais coerente pensar que a intencionalidade husserliana não coincide com essa teoria, uma vez que - independentemente de ter ou não existido historicamente - ela considera a intencionalidade como um dado, pretendendo tomar como fundamento aquilo que na investigação husserliana é um enigma a ser esclarecido: o a priori da correlação ou a correlação transcendental entre o mundo e a subjetividade, entendida não mais como a correlação entre sujeito e objeto no interior do mundo, e sim como a relação entre o conhecimento e o objeto reduzido, quer dizer, entre o conhecimento imanente e a transcendência posta pela imanência mesma. Aliás, como afirma Ribeiro de Moura (1989, p. 35), o fato mesmo de a intencionalidade brentaniana ser tomada como um dado talvez a torne estéril para a Filosofia, uma vez que, além de não fazer mais do que repetir o que teria sido a "intencionalidade dos escolásticos", ela também não desperta interesse do ponto de vista da interlocução com o pensamento moderno, uma vez que não põe o problema radical da possibilidade do conhecimento objetivo.

\section{Edith Stein e o pensamento medieval}

Parece ser outro o caso de Edith Stein. Ela reabilita explicitamente formas do pensamento medieval ou "escolástico" (como ela dizia, embora, segundo o que se observa principalmente em Ser finito e eterno, ela ponha sob a etiqueta "escolásticos" autores muito diferentes, como Agostinho de Hipona, Dionísio Pseudoareopagita, Tomás de Aquino e Duns Escoto, entre outros).

Terá Edith Stein simplesmente "retornado" aos medievais depois de ter sido fenomenóloga? Como gostam de dizer alguns neotomistas, 
terá ela vagado por estradas filosóficas suspeitas, até retornar à boa, límpida e perene doutrina neotomista? A propósito, há também neotomistas que consideram Edith Stein uma má discípula de Tomás, afirmando que ela não restitui a "doutrina ortodoxa" do Doutor Angélico, como se houvesse um pensamento homogêneo e monolítico na obra de Tomás (cf., por exemplo, GABORIAU, 1999). Falando de tomismo ou de neotomismo, convém lembrar que a divisão da obra de Edith Stein em três fases (etapa fenomenológica, etapa cristã e etapa cristã-mística) é claramente inadequada, pois dá a entender que Edith Stein terá abandonado a fenomenologia em benefício do pensamento cristão, coisa que não se observa nos seus textos.

$\mathrm{Na}$ contrapartida da visão de Edith Stein como alguém que se converteu aos medievais está a sua imagem como uma "fenomenóloga do começo ao fim", tal como a descreve, por exemplo, Hedwig ConradMartius (1958). Sendo uma fenomenóloga estrita, ela apenas ativaria formas medievais de pensar para confirmar ou suscitar análises fenomenológicas.

Nenhuma dessas maneiras de classificá-la parece adequada. Basta analisar com cuidado o modo como Edith Stein trata os medievais para observar que ela não é uma simples repetidora de Tomás de Aquino ou de outro autor, nem uma fenomenóloga que recorre casual ou acidentalmente aos medievais. Para ilustrar o seu trabalho, tomemos aqui dois exemplos precisos: (i) sua reelaboração do assim chamado "argumento ontológico" de Anselmo da Cantuária; (ii) sua interpretação steiniana da concepção tomasiana da abstração:

(i) Edith Stein assimila o argumento dito "ontológico" de Santo Anselmo, pretendendo, no entanto, "melhorá-lo", pois, no seu dizer, seu próprio argumento tem melhor funcionamento ao estabelecer uma compreensão elementar de Deus mais clara. Com efeito, em Ser finito e eterno III, 12, a filósofa pretende evitar as dificuldades que implicava a definição anselmiana de Deus como "aquilo de que nada de maior pode ser pensado" e propõe tomar a concepção tomasiana de Deus como "aquilo cuja essência é existir" (id cujus essentia est esse / das dessen Wesen das Sein ist). Tal noção seria melhor por permitir distinguir entre os entes finitos, cuja essência não pode ser realmente separada de sua existência, embora tal essência e tal existência possam ser pensadas 
separadamente e o primeiro ente, Deus, cuja essência não pode nem mesmo ser pensada à parte de sua existência, pois, se afastarmos pelo pensamento seu existir, não restará nada. Edith Stein, como se vê, assimila e reelabora o argumento anselmiano. Ela não o altera em sua forma, pois o argumento continua a inferir a realidade do ente absoluto com base na ideia do ente absoluto, mas altera a ideia do ente absoluto, a fim de evitar a crítica tomasiana ou "empirista" segundo a qual o argumento de Anselmo opera uma passagem injustificada da lógica para a ontologia. A propósito, Edith Stein acerta na mudança da definição do ente absoluto - independentemente de sua exegese de Anselmo ser ou não correta - porque, no modo como o argumento é montado, cair-se-ia de fato em uma falácia se se procedesse do pensamento para a coisa. Ora, como o argumento steiniano se restringe a uma essência que é seu próprio existir e aplica-se somente a Deus (indo, portanto, da essência ao existir), então ele é válido, além de fornecer finalmente a razão de Deus ser o "maior" e o "mais perfeito" dos entes: a sua essência é o seu existir, razão pela qual Deus não pode ser pensado separadamente de seu existir ${ }^{1}$;

(ii) engana-se, porém, quem ouve a expressão "crítica tomasiana ou 'empirista'”, proferida há pouco, e entende que o pensamento de Tomás de Aquino é interpretado por Edith Stein como um tipo de empirismo ou de filosofia que pressupõe uma teoria do conhecimento objetivista na qual o objeto externo determina integralmente o conhecimento. O caráter, digamos, "empirista" da crítica tomasiana ao argumento ontológico justifica-se por sua exigência de ir da coisa para o pensamento, mas isso não quer dizer que o pensamento tomasiano seja uma forma de empirismo ou de compreensão do intelecto ou da consciência como tabula rasa. A esse respeito, no texto A fenomenologia de Edmund Husserl e a filosofia de Santo Tomás de Aquino (2014), Edith Stein insiste no que ela considera uma coincidência de Tomás com a fenomenologia, quer dizer, a defesa de que todo conhecimento humano natural adquire-se por meio de uma elaboração intelectual de um material sensível: o intelecto que divide e une, do qual fala Tomás, realiza uma atividade que se exprime,

1 Para um estudo detalhado da compreensão steiniana do argumento de Anselmo de Cantuária, ver Walter Redmond, 2016. 
em fenomenologia, como o prescindir de tudo aquilo que corresponde à coisa de modo apenas acidental; trata-se deuma orientação da visada para o que corresponde à coisa material como tal, ao que pertence à ratio da coisa material. A abstração tomasiana não seria, portanto, uma abstração de tipo indutivista. Seria simplificar demais e trair o pensamento de Tomás de Aquino conceber o dividere e o componere como conclusões da indução e mesmo da dedução no sentido das ciências naturais empíricas e das formas tradicionais dos silogismos. Justamente por essa exegese singular do pensamento de Tomás de Aquino (sem ser uma adepta do tomismo transcendental!), Edith Stein também podia defender o reverso da mesma moeda: Husserl era em certa medida tomasiano, uma vez que ele aceitaria sem problema, segundo o quadro da exegese steiniana de Tomás, que todo conhecimento começa com os sentidos. Assim, ainda que ele seja considerado "pré-crítico" do ponto de vista da historiografia filosófica, o pensamento de Tomás de Aquino, segundo a leitura de Edith Stein, não deixa de proceder a certa crítica da razão ao pôr em questão o papel do intelecto na produção do conhecimento. Seja como for, o Tomás de Aquino de Edith Stein não é o do objetivismo ingênuo que Husserl pensava ser, tampouco o do empirismo indutivista como queria o neotomismo ${ }^{2}$.

\section{Da afectibilidade à filosofia do ser}

Esses dois exemplos mostram que Edith Stein comporta-se como uma filósofa que pensa com base em dois referenciais: sua formação fenomenológica e sua frequentação de autores medievais. Poderíamos dizer que ela presentifica esses autores e os conjuga com seu trabalho fenomenológico. Não é casual, por exemplo, que na fase madura de seu pensamento ela adote o par conceitual ato/potência como condições fundamentais do ente: no limite, é a existência temporal, marca central da experiência humana, que lhe permite pôr em diálogo direto

2 Para uma versão mais acessível (inclusive porque traduzida em português) do texto de Edith Stein sobre a fenomenologia de Husserl e a filosofia de Tomás de Aquino, ver Edith Stein, 2005a (artigo em forma de diálogo entre os dois pensadores). 
o pensamento medieval com a fenomenologia de Husserl e com a obra Ser e tempo de Heidegger. Ela não é, portanto, uma repetidora do patrimônio medieval - e antigo - em torno dessas noções, pois ela altera o modo mesmo de concebê-las.

Em virtude dessa alteração, podemos dizer que, na fase madura de seu pensamento, uma investigação de tipo metafísico vem complementar ou continuar a investigação fenomenológica, mas passando por mediações que justificam essa complementação ou continuidade, e nunca dando um salto que faria da metafísica o coroamento da fenomenologia. Mais do que extrapolar a fenomenologia, Edith Stein quis levá-la às últimas consequências, pois, no terreno dessas últimas consequências, no qual Husserl não quisera ou não pudera adentrar, Edith Stein via a base para a conexão com uma investigação de caráter metafísico. Trata-se de uma fronteira na qual a imanência mesma da consciência parece solicitar a afirmação da independência ôntica da efetividade. Afirmada tal independência (que já fora obtida, aliás, por meio da descrição da intersubjetividade), o par conceitual tomasino ato/potência permitiria descrever com mais clareza a estrutura última da efetividade. É o que parece possível obter do trecho registrado no fim do "Excurso sobre o idealismo transcendental", aposto quase ao final da obra Potência e ato (2005b), e mesmo já no prefácio da mesma obra.

Com efeito, tendo anunciado no Prólogo de Potência e ato sua intenção de produzir uma "filosofia do ser" que compusesse a fenomenologia com o pensamento de Tomás de Aquino, Edith Stein justifica-se, em resumo, dizendo que seu trabalho era filosófico, e não um trabalho típico das Ciências do Espírito: diante de um pensamento, a atividade das Ciências do Espírito consiste em estudar a articulação das razões internas desse pensamento, ao passo que a atividade da Filosofia consiste em compreender por que um pensador articulou suas razões da maneira como as articulou. Em Filosofia, buscar-se-ia chegar à experiência mesma que suscitou um pensamento, vivenciar suas causas, ser impressionado por elas e decidir-se por elas ou contra elas (seguindo o pensador estudado ou procurando outro caminho). É nesse nível que se pode pretender uma apropriação das razões de um filósofo, uma composição 
com elas ou ainda a recusa delas. Interessar-se apenas pela "lógica" ou "estrutura interna" de um pensamento significaria mantê-lo à distância como alvo de um interesse não propriamente filosófico (um interesse histórico, sociológico ou outro).

Dessa perspectiva, uma das justificativas de Edith Stein está no fato de ela declarar que sua experiência coincide com a experiência de Tomás de Aquino tal como ele a exprime em seus textos. A experiência de Edith Stein se vê retratada no modo como Tomás de Aquino registra a sua própria experiência ou a sua filosofia. Por essa coincidência profunda, então, parecia "natural" a Edith Stein dedicar-se a construir uma filosofia do ser de matriz fenomenológico-tomasiana. O caráter fenomenológico dessa filosofia do ser vinha, por sua vez, do fato de Edith Stein ter sido formada por Edmund Husserl e de ela assumir-se como uma seguidora de seu mestre. Assim, no limite, a prioridade de sua filosofia do ser é dada à "consciência do ser" (genitivo objetivo). É como fenomenóloga que ela busca uma filosofia do ser de inspiração tomasiana, ainda que, como ela mesma reconhece, encontrar tal filosofia pareceria extrapolar a fenomenologia.

Ao retomar o tema inicial do mencionado Excurso, o tema da sensação, Edith Stein serve-se de um exemplo bastante simples para ilustrar seu projeto: algo surge diante de meu olhar e desaparece antes que eu o perceba ou o retenha. Depois surge de novo e tenho a ocasião de examiná-lo. Vejo que é uma flor jogada ao vento. O exemplo mostra que o emergir de algo me faz reagir involuntariamente (levanto os olhos sem decidir por esse ato), para só depois agir voluntariamente (perceber e examinar). Interessa a Edith Stein a natureza involuntária da reação, porque essa natureza mostra haver uma emergência/aparição (Auftreten) de dados da sensação como dados na fronteira da imanência e da transcendência (dados de consciência imanente-transcendentes: immanent-transzendenter Bewusstseinsdater) que permanecem ininteligíveis ou impossíveis de elucidar na reflexão puramente imanente.

Dito de outra maneira, Edith Stein parece identificar um limite na análise do idealismo transcendental de Husserl e pretender ir além desse limite: recorde-se que, segundo Husserl, se se dá atenção à experiência 
na qual a transcendência da realidade da coisa ou do mundo de coisas se impõe à consciência (e que é o fundo da orientação natural), percebe-se que: (i) a transcendência do ente real não pode ser confundida com um simples sentido intencional (correlato de um modo subjetivo de apreensão) ou com uma compreensão, porque a experiência que doa originariamente o mundo é a experiência de ser afetado ou de receber afecção; (ii) esse ser afetado ocorre antes da doação de sentido e fora dela; (iii) a essência da transcendência consiste no seu manifestar antes de qualquer intencionalidade e mesmo sem ela; (iv) o que se doa antes da intencionalidade - e é mesmo sua condição de possibilidade ou sua possibilidade transcendental - é a síntese passiva originária da consciência do tempo; (v) mas essa síntese - que é a mais originária de todas e que gera e sustenta a possibilidade de toda visada intencional - repousa sobre a afecção ou a afeccionabilidade própria da afecção originária em sua atualidade. Em outras palavras, como afirma Jean-François Lavigne (2015), repousa na possibilidade ou na potência da afecção que garante e suporta a afecção originária em ato. Mas aqui Edith Stein parece ver o limite da fenomenalidade de Husserl; seria esse o ponto de originariedade diante do qual para ou estaciona o questionamento husserliano. Edith Stein parece querer justamente ir além desse ponto.

A filósofa parece querer ir além desse limite porque ela pergunta pelo que torna possível a afeccionabilidade ou a afectibilidade, quer dizer, em resumo, pela condição de possibilidade da síntese passiva. Esse "projeto" é o que parece explicar o porquê de Edith Stein dizer que no movimento involuntário há um saber vivencial/experiencial (Erfahrungswissen) a respeito do corpo (Körper), com sua posição, comportamento e movimentos, saber esse que leva o indivíduo a perceber-se como corpo vivo (Leib), união estreita entre materialidade e vida sensível/psíquica: vemo-nos como mais uma coisa entre outras (Körper), mas também nos vemos como seres diferentes, espirituais (Leib). Essa diferença é explicada por Edith Stein em termos da afecção que se revela no corpo psicofísico: somos preparados para ter afecções que não apenas manifestam um estímulo ou uma estimulação do corpo, mas que também têm uma função objetiva, a de atualizar ou trazer a ato a função específica do conhecimento dos sentidos ou a afeccionabilidade. 
A afeccionabilidade ou potência de receber afecção é a condição da sensação; ela permite a função dos sentidos. Ela é, por conseguinte, o elo com o mundo das coisas independente onticamente, uma vez que o saber sobre o próprio corpo vivo se faz pelos nexos envolvendo o corpo e a doação das coisas na percepção. É o vê-las como existentes e diferentes de mim, assim como vejo outros corpos humanos como existentes e diferentes de mim, que me dá o meu saber sobre mim mesmo. A doação das coisas é valorizada, então, tanto quanto a experiência intersubjetiva; Edith Stein não admite a irracionalidade dessa doação ou o seu caráter de "resíduo irracional", como, no seu dizer, pensava Husserl. Antes, sua inteligibilidade é garantida pela afectibilidade; e conhecer não deixará de significar conhecer-se a si mesmo.

O risco dessa "radicalização" da fenomenologia e da conexão com o mundo exterior parece estar, obviamente, em abrir espaço para a filosofia da representação de tipo empirista que concebe a consciência como tabula rasa. No entanto, a afectibilidade e a autodoação das coisas, condição para a doação de sentido pela consciência, não significa, para Edith Stein, algo como uma "heteronomia da afecção". A conexão dos dados da sensação e das espécies sensíveis com o mundo exterior ou a ideia de que as coisas "caem" sob os sentidos significa que o sujeito é objetivamente orientado (gegenständlich gerichtetes), aberto ao objeto como sujeito intelectual. Cada intuição não é meramente sensível: o material sensível aparece como aquilo que preenche uma "estrutura" formal, porém não como algo elaborado por formas estruturais, tais como as formas da sensibilidade e as categorias do entendimento em termos kantianos, mas como aquilo cuja presença fornece um sentido para cuja "leitura" ou "interpretação" o sujeito está preparado.

Ainda, uma forma de coisa corresponde a certas formas de ato (Dingformen/Aktformen). A rigor, a consciência não é formada "de fora", mas é estimulada por coisas de fora. Tudo se resolve no presente ou na vida atual do sujeito, segundo Edith Stein, inclusive a recordação e a fantasia, salvo que nesses atos a crença na existência não é implicada. Tal crença é sim implicada e legítima na percepção direta. De certa maneira, na visão de Edith Stein, dizer isso é uma consequência da própria redução que punha tal crença fora de circuito. É também encontrar o 
pensamento tomasiano, que, sem ser ingenuamente objetivista, dá prioridade à função objetiva de atualizar a função específica do conhecimento dos sentidos ou a afeccionabilidade, ao mesmo tempo em que também prioriza o subjetivismo que reconhece a função do intelecto de produzir conhecimento como elaboração propriamente intelectual de um material sensível. Dessa perspectiva, conhecer é não apenas conhecer a si mesmo, mas é rigorosamente também conhecer a alteridade dos objetos. Tal alteridade permitirá clarear, ainda, a ideia de ser e de infinitude, conduzindo mesmo à afirmação metafísica de um fundamento transcendente (uma segunda transcendência) para os entes.

\section{Considerações finais}

Ao comportar-se como uma filósofa de formação fenomenológica e que - como ela mesma afirma principalmente no prefácio de Potência e ato - revive razões de autores medievais, Edith Stein produz um pensamento que pode ser considerado uma conjugação ou uma articulação harmônica (não uma síntese!) entre fenomenologia e releitura do patrimônio filosófico (incluindo o antigo e o moderno, não apenas o medieval). Para além de toda etiqueta, convém dar a esse pensamento o nome que a própria filósofa deu: uma filosofia do ser.

Não nos enganemos, porém, pensando que Edith Stein volta a um objetivismo no qual o ser simplesmente se daria a nós. Lembremos o subtítulo de Ser finito e eterno: trata-se de um ensaio de ascensão ao sentido do ser. Esse detalhe é de extrema importância, pois permite enfatizar algo que, mesmo Edith Stein tendo repetido em vários lugares de Potência e ato e de Ser finito e eterno, é em geral negligenciado por muitos estudiosos: o objetivo de sua filosofia era dialogar com a Modernidade; era enfrentar os problemas que a filosofia punha no seu tempo. Assim, se depois de ter sido enxotado das filosofias modernas majoritárias o ser retornava à cena filosófica, Edith Stein fez dele o seu tema principal, mas sem deixar de ter em vista que, para tratar do ser de modo filosoficamente adequado, era preciso dialogar com os modernos. É nesse projeto que se insere, a meu ver, sua reabilitação de formas filosóficas medievais. 


\section{Referências}

BOULNOIS, O. Heidegger, l'onthothéologie et les structures médiévales de la métaphysique. Le Philosophoire, v. 3, n. 9, p. 27-55, 1999.

CONRAD-MARTIUS, H. Meine Freundin Edith Stein. Hochland, v. 51, p. 38-48, 1958. GABORIAU, F. Edith Stein philosophe. Paris: François-Xavier de Guibert, 1999. HUSSERL, E. Logische Untersuchungen. V. II-1. Tubinga: M. Niemeyer, 1968. LAVIGNE, J.-F. En deçà du transcendental: les conditions pré-phénoménales de la vie transcendentale. Metodo. International Studies in Phenomenology and Philosophy. Special Issue, v. 1, n. 1, p. 83-102, 2015.

REDMOND, W. O argumento ontológico de Edith Stein. TQ - Teologia em questão, v. 30, n. 2, p. 73-100, 2016.

RIBEIRO DE MOURA, C. A. Crítica da razão na fenomenologia. São Paulo: EDUSP \& Nova Stella, 1989.

STEIN, E. Endliches und ewiges Sein. Friburgo na Brisgóvia: Herder, 2016. (Edith Stein Gesamtausgabe, v. 11/12).

STEIN, E. Husserls Phänomenologie und die Philosophie des hl. Thomas von Aquino. In: STEIN, E. "Freiheit und Gnade" und weitere Beiträge zu Phänomenologie und Ontologie. Friburgo na Brisgóvia: Herder, 2014. (Edith Stein Gesamtausgabe, v. 9).

STEIN, E. O que é filosofia? Uma conversa entre Edmund Husserl e Tomás de Aquino. Scintilla - Revista de filosofia e mística medieval, v. 2, n. 2, p. 301-332, jul./dez. 2005a.

STEIN, E. Potenz und Akt. Friburgo na Brisgóvia: Herder, 2005b. (Edith Stein Gesamtausgabe, v. 10).

Recebido: 26/08/2017

Received: 08/26/2017

Aprovado: $15 / 09 / 2017$

Approved: 09/15/2017 